\title{
Correction to: Kaplan-Meier Survival Curves and the Log-Rank Test
}

\section{David G. Kleinbaum and Mitchel Klein}

\section{Correction to: \\ Chapter 2 in: D. G. Kleinbaum, M. Klein, Survival Analysis: A Self-Learning Text, Third Edition, Statistics for Biology and Health, https://doi.org/10.1007/978-1-4419-6646-9_2}

The original version of this chapter was revised. In page 63 of Chapter 2 , in the $4^{\text {th }}$ paragraph, the text "2 people failed at 2 week" has been changed to " 2 people failed at 1 week" and "survivors past 2 week" has been changed to "survivors past 1 week." 